\title{
TAFRO syndrome with skin manifestations treated with bortezomib and tocilizumab; a case report
}

\author{
Seyedeh Tahereh Mohaddess ${ }^{1}{ }^{\mathbb{D}}$, Zahra Rezaei Borojerdi ${ }^{*}{ }^{(\mathbb{D}}$, Maryam Miri $^{2}$, Mohammad Moeini Nodeh $^{1}$, Alireza \\ Rezaei $^{3}$, Mahin Ghorban Sabbagh², Samane Sajjadi ${ }^{1}$, Fatemeh Seyyedi Khabbaz ${ }^{1}$, Amin Ranjbar ${ }^{1}$
}

${ }^{1}$ Hematology Oncology Department, Internal Medicine Department, Ghaem Hospital, Mashhad University of Medical Sciences, Mashhad, Iran

${ }^{2}$ Kidney Transplantation Complications Research Centre, Mashhad University of Medical Sciences, Mashhad, Iran

${ }^{3}$ Department of Pathology, Islamic Azad University of Medical Sciences, Mashhad, IR Iran

*Correspondence to Zahra Rezaei Borojerdi, Email: rezaeibz961@mums.ac.ir

Received 19 April 2019 Accepted 10 August 2019 ePublished 10 September 2019

Keywords: Bortezomib, mesangioproliferative glomerulonephritis, Tocilizumab, Castleman disease, Hemangioma, Glomerulonephritis

Citation: Tahereh Mohaddess ST, Rezaei Borojerdi Z, Miri M, Moeini Nodeh M, Rezaei A, Ghorban Sabbagh M. TAFRO syndrome with skin manifestations treated with bortezomib and tocilizumab; a case report. Immunopathol Persa. 2020;6(1):e01. DOI:10.15171/ipp.2020.01

\section{Abstract}

TAFRO syndrome is a new presentation of idiopathic multicentric Castleman disease which is termed as thrombocytopenia, anasarca, myelofibrosis, renal failure and organomegaly (TAFRO). The exact pathophysiology of TAFRO syndrome is unclear and management is mostly based on case reports and expert opinion. In this report, a 37 years old male patient with TAFRO syndrome is discussed. The patient was referred with fever, sweating, anorexia, abdominal distension and generalized edema which has been hospitalized multiple times for such complaints. The patient also developed skin lesions dispersed in red nodules, which was reported as "granuloid hemangioma". Renal biopsy suggested mesangioproliferative glomerulonephritis and bone marrow specimen showed hypercellular active marrow with reticulin fibrosis. The lymph node biopsies were reported as Castleman disease. This report demonstrates that different manifestations of TAFRO syndrome may overlap with other syndromes and can be managed by Bortezomib and Tocilizumab.
Introduction

Castleman disease (CD) is a lymphoproliferative disorder with many poorly understood pathophysiological aspects. The two main types of CD include unicentric Castleman disease (UCD) and multi-centric Castleman disease (MCD). The MCD type has 2 main subtypes depending on human herpesvirus-8 (HHV8) infection status. IdiopathicMCD and polyneuropathy, organomegaly, endocrinopathy, monoclonal gammopathy, and skin change (POEMS)-associated MCD are 2 subtypes of HHV-8 negative MCD (1). Recently, a new presentation of idiopathic-MCD is proposed, which is termed as thrombocytopenia, anasarca, fibrosis, renal failure and organomegaly (TAFRO) syndrome. Presentations of CD vary completely according to different subtypes. In contrast to UCD, which is usually presented with localized masses in mediastinum and neck, the MCD presents

\section{Key point}

TAFRO syndrome is a new presentation of idiopathic multicentric Castleman disease which is termed as thrombocytopenia, anasarca, myelofibrosis, renal failure and organomegaly (TAFRO)

with multiple lymphadenopathy and multiorgan involvement along with systemic features (1). These patients usually present with generalized malaise, fever, anorexia and weight loss and laboratory investigations may reveal thrombocytopenia. The diagnosis is usually made histologically since the hallmark finding is typical interfollicular plasmacytosis in lymph nodes. Regarding the fact that $\mathrm{CD}$ is a rare disease, the optimal treatment is still controversial. Treatment may vary based on the type of $\mathrm{CD}$ and clinical condition of the patients, from surgical removal of lesions in UCD to different chemotherapy regimens in MCD. TAFRO syndrome as a newer

\footnotetext{
Copyright (C) 2020 The Author(s); Published by Nickan Research Institute. This is an open-access article distributed under the terms of the Creative Commons Attribution License (http://creativecommons.org/licenses/by/4.0), which permits unrestricted use, distribution, and reproduction in any medium, provided the original work is properly cited.
} 
subtype of CD is not widely studied in terms of diagnosis or treatment. Management and treatment of TAFRO syndrome is usually made according to case reports and expert opinions. In this case report, we will discuss a case of TAFRO syndrome with skin manifestations which was managed successfully.

\section{Case Report}

A 37-year-old man, referred to outpatient clinic with the chief complain of fever, sweating, anorexia, abdominal distension and generalized edema which has been developed gradually since two years ago. The clinical course started 2 years ago while the patient was admitted in a general hospital several times because of similar presentations. In the primary admission, on physical examination unilateral axillary lymphadenopathy with an approximate diameter of $1.5 \mathrm{~cm}$ was prominent. Ascites, pericardial effusion and peripheral pitting edema were also notable. Laboratory tests revealed thrombocytopenia of $43000 / \mu \mathrm{L}$ (normal range $=150000 / \mu \mathrm{L}$ to $450000 / \mu \mathrm{L}$ ) and normochromic normocytic anemia. Urine analysis showed protein excretion within the range of nephrotic syndrome. Ascites fluid analysis showed low serum ascites albumin gradient and pleural fluid was transudate. Ascites cytology was negative for malignancy. The patient had renal impairment since the serum creatinine level was approximately $2 \mathrm{mg} / \mathrm{dL}$ and erythrocyte sedimentation rate was $113 \mathrm{~mm} / \mathrm{h}$. Abdominal ultrasonography showed a brief splenomegaly $(131 \mathrm{~mm})$ and a sever ascites was detected. Cardiac examination showed pericardial effusion. During admission, the ascites fluid was drained. A year later, previous clinical problems continued and anemia intensified. Abdominal and pelvic ultrasonography showed splenomegaly, multiple mesenteric lymphadenopathy and ascites. Ascites cytology was negative for malignancy. Upper gastrointestinal tract endoscopy was normal. The thoracic computed tomography (CT) scan showed a soft tissue density which was identified in upper mediastinum with high probability of an increased thymus magnitude. In the abdominal and pelvic CT scan, periportal and iliac lymphadenopathy with an approximate diameter of 20 $\mathrm{mm}$ was prominent. Dense ascites was also detected. Color Doppler ultrasound scan of supra-hepatic and portal veins was normal. Peritoneal biopsy revealed fibrinous serositis. Evaluation of infectious diseases including tuberculosis and viral markers including human immunodeficiency virus (HIV) test were negative. Furthermore, rheumatologic tests including antinuclear antibody, anti-double stranded DNA (DS-DNA), serum complements, were within normal limits. Two years later, in addition to the previous symptoms, ascites, edema, and renal failure aggravated while the size of the previous lymph nodes increased and lymphadenopathy became generalized. The patient also developed skin lesions dispersed in red nodules, which was reported as "granuloid hemangioma" in pathological study (Figure 1). Renal biopsy pathology reported was mesangioproliferative glomerulonephritis. Abdominal and pelvic CT scans revealed splenomegaly of about 15 $\mathrm{cm}$ and mesenteric and para-aortic lymphadenopathy and mesenteric diffusion infiltration were also reported. Bone marrow pathology result was as follows; hypercellular active marrow with reticulin fibrosis (Grade III) (Figure 2). Investigation for Janus kinase 2 (JAK2) gene mutation was negative. The patient underwent diagnostic laparoscopy and extensive fibroid lesions on the surface of the peritoneum with multiple adhesions were detected. Excisional inguinal lymph node biopsy was performed (Figure 3). Due to the symptoms of thrombocytopenia, anasarca edema, history of myelofibrosis, renal failure and organomegaly (splenomegaly), along with the diagnosis of Castleman disease based on lymph node biopsy, TAFRO syndrome was diagnosed for the patient. Further assessments revealed that serum interleukin 6 (IL-6) levels have increased in this patient. The cytogenetic study revealed normal male with 46 chromosomes. HHV8 was negative in lymph node test. Due to the rarity of TAFRO syndrome, based on our literature review for possible treatment, a combination regimen was administered. The regimen was initiated with tocilizumab $(400 \mathrm{mg})+$

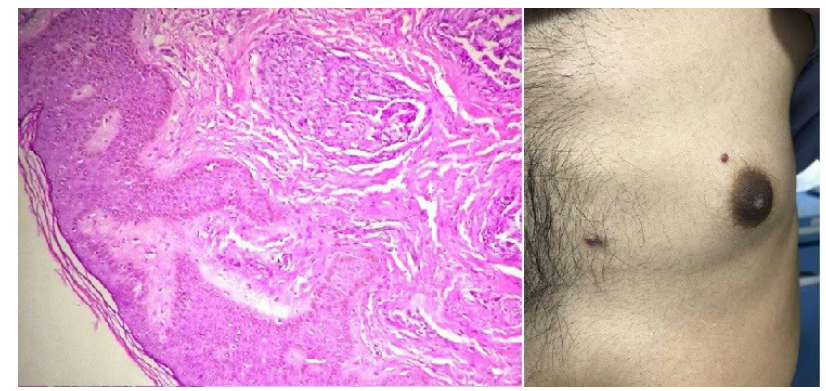

Figure 1. Bright red nodular lesion on chest and skin biopsy showed lobular proliferation of closely packed capillary vessels contains RBC (H\&E) (X100).

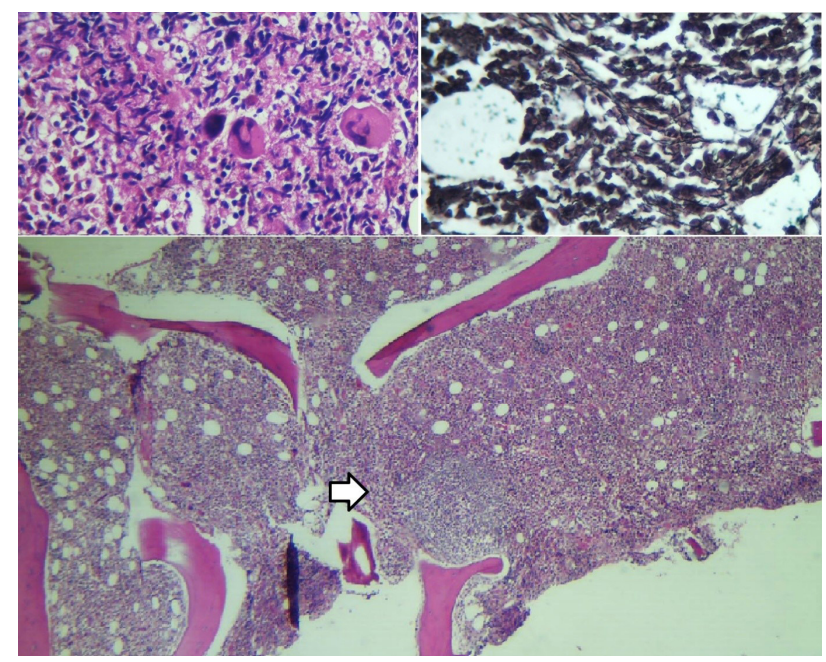

Figure 2. Upper images: Increased marrow megakaryocytes with mild atypia and reticulin fibers (left: H\&E - Righ ; Reticulin) (X400). Down image: Hypercellular marrow with Regressed germinal centre (arrow) (H\&E) (X100). 


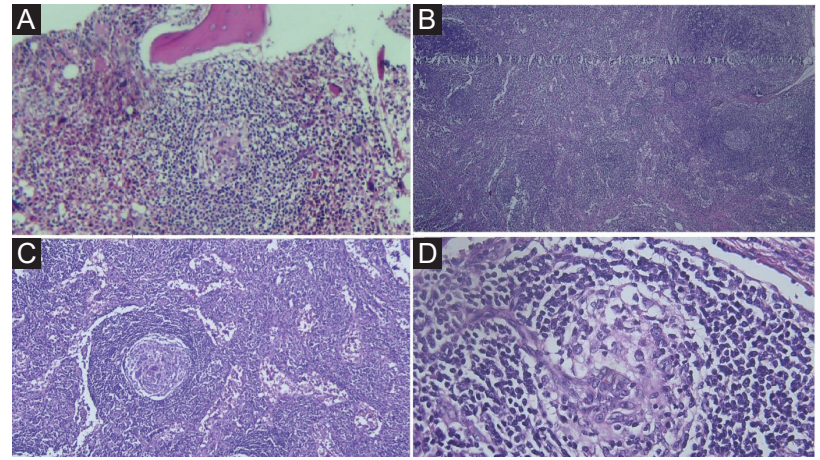

Figure 3. A: regressed germinal centre and expanded concentric mantle zones and increased megakaryocytes (H\&E) (X200). B: lymph node showed scattered lymphoid follicles with atrophic germinal centres and enlarged mantle zone (H\&E) (X100). C: Expanded mantle zone with concentric ring of small lymphocytes (H\&E) (X100). D: Regressed germinal centre with surrounded onion skinning mantle zone and penetrating blood vessel (H\&E) (X400).

prednisolone $(50 \mathrm{mg}$ ). Within less than one month, his edema began to resolve. The laboratory studies during the treatment period are summarized in Table 1. So far, the patient's treatment continued for 4 months but unfortunately because of the patient's refusal, treatment was terminated by his decision and he did not continue the follow up visits. Approximately two months later the patient returned to the clinic with clinical relapse of symptoms. At this time a new treatment regimen, weekly rituximab (600 $\mathrm{mg}$ ) and bortezomib (2.5 mg), was administered. The patient well tolerated and responded to bortezomib and became symptom free within four months since the treatment is still ongoing.

\section{Ethical approval}

The patient gave his consent to publish as a case report. This case report was approved by the ethical committee of Mashhad University of Medical Sciences for publication(ref\#98/139628).

\section{Discussion}

MCD is a rare type of lymphoproliferative disorders, which is characterized according to its laboratory findings. POEMS and TAFRO syndromes are two subtypes of MCD which are both HHV8 negative. Despite the wellknown differences between these two subtypes, which are understandable from their numen culture, we think that overlap of these syndromes should be taken into account (2). Our patient had all the major criteria for TAFRO syndrome including anasarca edema, thrombocytopenia

Table 1. The laboratory studies of the patient during the treatment period

\begin{tabular}{|c|c|c|c|c|c|c|c|}
\hline $\begin{array}{l}\text { Laboratory } \\
\text { findings }\end{array}$ & $\begin{array}{l}\text { At the } \\
\text { presentation(before } \\
\text { treatment) }\end{array}$ & $1^{\text {st }}$ month & $\begin{array}{c}\text { End of the } 2^{\text {nd }} \\
\text { month }\end{array}$ & $3^{\text {rd }}$ month & $4^{\text {th }}$ month & $\begin{array}{l}\text { After the } 2 \\
\text { months of } \\
\text { the patient's } \\
\text { treatment } \\
\text { refusal }\end{array}$ & $\begin{array}{c}6^{\text {th }} \text { month } \\
\text { (normal ranges) }\end{array}$ \\
\hline $\begin{array}{l}\text { Blood urea } \\
\text { nitrogen }\end{array}$ & $29 \mathrm{mg} / \mathrm{dL}$ & $23 \mathrm{mg} / \mathrm{dL}$ & $27 \mathrm{mg} / \mathrm{dL}$ & $25 \mathrm{mg} / \mathrm{dL}$ & $27 \mathrm{mg} / \mathrm{dL}$ & $28 \mathrm{mg} / \mathrm{dL}$ & $15 \mathrm{mg} / \mathrm{dL}(5-54)$ \\
\hline Creatinine & $2 \mathrm{mg} / \mathrm{dL}$ & $1.1 \mathrm{mg} / \mathrm{dL}$ & $1.1 \mathrm{mg} / \mathrm{dL}$ & $0.9 \mathrm{mg} / \mathrm{dL}$ & $1.1 \mathrm{mg} / \mathrm{dL}$ & $2 \mathrm{mg} / \mathrm{dL}$ & $1 \mathrm{mg} / \mathrm{dL}(0.5-1.5)$ \\
\hline $\begin{array}{l}\text { Red blood } \\
\text { cell }\end{array}$ & $3.1010^{\wedge} 12 / \mathrm{L}$ & $3.3710^{\wedge} 12 / \mathrm{L}$ & $4.5610^{\wedge} 12 / \mathrm{L}$ & $5.2710^{\wedge} 12 / \mathrm{L}$ & $4.9610^{\wedge} 12 / \mathrm{L}$ & 3.91 10^12/L & $4.3410^{\wedge} 12 / L(4.3-6)$ \\
\hline Hemoglobin & $8.7 \mathrm{~g} / \mathrm{dL}$ & $9.7 \mathrm{~g} / \mathrm{dL}$ & $13.8 \mathrm{~g} / \mathrm{dL}$ & $15.9 \mathrm{~g} / \mathrm{dL}$ & $15.5 \mathrm{~g} / \mathrm{dL}$ & $11.3 \mathrm{~g} / \mathrm{dL}$ & $13.3 \mathrm{~g} / \mathrm{dL}(13-17.2)$ \\
\hline Platelet & $4310^{\wedge} 9 / \mathrm{L}$ & $18410^{\wedge} 9 / \mathrm{L}$ & $20210^{\wedge} 9 / \mathrm{L}$ & $21210^{\wedge} 9 / \mathrm{L}$ & $20110^{\wedge} 9 / \mathrm{L}$ & $14210^{\wedge} 9 / \mathrm{L}$ & $\begin{array}{c}26410^{\wedge 9 / L}(150- \\
450)\end{array}$ \\
\hline \multirow[t]{3}{*}{$\begin{array}{l}\text { Erythrocyte } \\
\text { sediment } \\
\text { rate }\end{array}$} & $113 \mathrm{~mm} / \mathrm{h}$ & $30 \mathrm{~mm} / \mathrm{h}$ & $2 \mathrm{~mm} / \mathrm{h}$ & $2 \mathrm{~mm} / \mathrm{h}$ & $2 \mathrm{~mm} / \mathrm{h}$ & $106 \mathrm{~mm} / \mathrm{h}$ & $30 \mathrm{~mm} / \mathrm{h}(0-15)$ \\
\hline & $\begin{array}{l}\text { After first dose } \\
\text { of intravenous } \\
\text { Tocilizumab } \\
\text { (400 mg) and } \\
\text { prednisolone ( } 50 \\
\text { mg/d) }\end{array}$ & $\begin{array}{l}\text { After first dose } \\
\text { of intravenous } \\
\text { Tocilizumab } \\
\text { (400 mg) and } \\
\text { prednisolone (50 } \\
\text { mg/d) }\end{array}$ & $\begin{array}{l}\text { After forth dose } \\
\text { of Tocilizumab } \\
\text { (400mg) and } \\
\text { first dose of } \\
\text { prednisolone ( } 12.5 \\
\text { mg/daily) }\end{array}$ & $\begin{array}{c}\text { After fifth dose } \\
\text { of Tocilizumab } \\
\text { (400 mg) and } \\
\text { prednisolone (10 } \\
\text { mg/daily) }\end{array}$ & $\begin{array}{l}\text { Tocilizumab } \\
\text { (400 mg) and } \\
\text { prednisolone } \\
\text { (10mg/daily) }\end{array}$ & $\begin{array}{l}\text { Initiation of } \\
\text { therapy with } \\
\text { Rituximab } \\
(600 \mathrm{mg}) \text { and } \\
\text { Bortezomib } \\
(2.5 \mathrm{mg}) \\
\text { weekly }\end{array}$ & $\begin{array}{c}\text { After } 3 \text { weeks of } \\
\text { rituximab (600 mg) } \\
\text { and Bortezomib ( } 2.5 \\
\text { mg) therapy. }\end{array}$ \\
\hline & $\begin{array}{l}\text { Ascites, } \\
\text { constipation, } \\
\text { pitting edema of } \\
\text { lower limb presents } \\
\text { and cervical } \\
\text { lymphadenopathy } \\
\text { vanished } \\
\text { and cervical } \\
\text { lymphadenopathy } \\
\text { shrinked. }\end{array}$ & $\begin{array}{c}\text { Ascites, } \\
\text { constipation, } \\
\text { pitting edema } \\
\text { of lower } \\
\text { limb presents } \\
\text { and cervical } \\
\text { lymphadenopathy } \\
\text { vanished } \\
\text { and cervical } \\
\text { lymphadenopathy } \\
\text { shrinked. }\end{array}$ & $\begin{array}{c}\text { Edema resolved } \\
\text { completely. Axillary } \\
\text { and inguinal } \\
\text { lymphadenopathy } \\
(1 * 1 \mathrm{~cm} \text { in diameter }) \\
\text { persists. }\end{array}$ & $\begin{array}{l}\text { No ascites and } \\
\text { edema. Right side } \\
\text { lymphadenopathy } \\
\text { disappeared. }\end{array}$ & $\begin{array}{l}\text { No ascites and } \\
\text { edema. No } \\
\text { splenomegaly. }\end{array}$ & $\begin{array}{l}\text { Generalized } \\
\text { edema and } \\
\text { ascites. }\end{array}$ & $\begin{array}{l}\text { Edema began to } \\
\text { resolve. }\end{array}$ \\
\hline
\end{tabular}


and systemic inflammation. Also, all the minor criteria of $\mathrm{CD}$ features on lymph node biopsy, reticulin myelofibrosis, organomegaly and progressive renal insufficiency were present. While our patient had all TAFRO syndrome characteristic findings, some presentations were not included among the reported criteria, including skin lesions (2). According to POEMS diagnostic criteria, which include skin lesions, our patient did not have polyneuropathy, which is a mandatory major criterion for POEMS (3). Only minor criteria including organomegaly, extravascular overload and skin changes were present, which made the diagnosis of POEMS less likely (3). Skin manifestation is usually seen with POEMS syndrome; however, our case has skin findings as well. Noda-Narita et al reported a case of TAFRO syndrome with multiple raised erythematous lesions on the trunk, which was similar to our patient (4). However, they did not mention the exact pathology result of the lesions. Such cases demonstrate the overlap between these two types of MCD. There are other cases demonstrating this overlap. Presence of neuropathy is also seen in TAFRO patients while this presentation is mostly seen with POEMS (5). Regardless of different and overlapping presentations, managing TAFRO is another challenge. Treatment of TAFRO syndrome mostly relies on combination therapy. The cornerstone of therapy is first based on corticosteroid therapy. While some patients were not responding to corticosteroids, researchers tried to add other drugs including tocilizumab (3). Other treatment regimens have been successfully administered in TAFRO syndrome. Kikuchi et al administered a regimen of tocilizumab, prednisone and cyclophosphamide (6). They suggested that addition of cyclophosphamide to tocilizumab and prednisone could be helpful in managing disease activity and remission of steroid refractory cases and severe forms. Addition of cyclophosphamide may reduce the therapeutic dose of steroids and reduce the adverse effects of steroid (6). Aoki et al reported a case of TAFRO syndrome which did not respond to tocilizumab (5). They suggested that rituximab is a good choice in patients who do not respond to tocilizumab therapy (5). The latest treatment, which is recently used in TAFRO cases, is bortezomib. The use of bortezomib is directly related to the role of IL6 in TAFRO pathogenesis. Although there is little known about the exact pathogenesis of TAFRO syndrome, it has been proposed that IL6, as a major proinflammatory cytokine, is responsible for a variety of presentations including fever, anemia and platelet production (7). Although the role of IL6 is more prominent in other forms of idiopathic MCD than TAFRO syndrome, some TAFRO cases respond to bortezomib, which is a selective proteasome inhibitor. Bortezomib decreases IL6 levels, inhibits the nuclear factor kappa B $(\mathrm{NF}-\kappa \mathrm{B})$ and induces the remission in idiopathic MCD (7). Methylprednisolone and tocilizumab combination can also rapidly stop IL6 mediated inflammation (8). Our case, similar to the previously reported cases, responded well to tocilizumab (9-11).

Conclusion

TAFRO syndrome is a rare form of CD and may present in various forms. Diagnosis and treatment of this syndrome could be challenging. Different manifestations of TAFRO syndrome may overlap with many other syndromes, including POEMS, since physicians should be fully aware of such differential diagnosis. While the exact pathophysiology of TAFRO syndrome is not clear, treatment is still based on case reports and expert opinion. According to our experience, TAFRO syndrome can be treated by use of tocilizumb, prednisolon, bortezomib and rituximab.

\section{Authors' contribution}

STM and ZRB designed the study. ZRB, MMGN, MMN and ARi performed the experiments. ZRB, MGS and STM analyzed the data. SS, FSK and AR wrote the manuscript. All authors approved the final version of the manuscript.

Conflicts of interest

The author declared no competing interests.

Ethical considerations

Ethical issues including plagiarism, double publication, and redundancy have been completely observed by the author. The patients gave his consent to publish as a case report.

\section{Funding/Support}

None.

\section{References}

1. Waterston A, Bower M. Fifty years of multicentric Castleman's disease. Acta Oncol. 2004; 43: 698-704. DOI:10.1080/02841860410002752.

2. 2.Masaki $\mathrm{Y}$, Kawabata H, Takai K, Kojima M, Tsukamoto N, Ishigaki $Y$, et al. Proposed diagnostic criteria, disease severity classification and treatment strategy for TAFRO syndrome, 2015 version. Int J Hematol. 2016;103:686-92. doi: 10.1007/ s12185-016-1979-1.

3. Dispenzieri A. POEMS syndrome: 2017 update on diagnosis, risk stratification, and management. Am J Hematol. 2017; 92: 814-29. doi: 10.1002/ajh.24802.

4. 4.Noda-Narita S, Sumida K, Sekine A, Hoshino J, Mise $\mathrm{K}$, Suwabe T, et al. TAFRO syndrome with refractory thrombocytopenia responding to tocilizumab and romiplostim: a case report. CEN Case Rep.2018; 7: 162-8. doi: 10.1007/ s13730-018-0319-0.

5. Aoki T, Wada M, Kawashima A, Hirakawa K, Nagata A, Kagawa K.Tocilizumab-resistant TAFRO Syndrome Complicated by Type II Respiratory Failure. Intern Med.2017; 56: 3249-54. doi: 10.2169/internalmedicine.8360-16.

6. 6. Kikuchi T, Shimizu T, Toyama T, Abe R, Okamoto SH. Successful Treatment of TAFRO Syndrome with Tocilizumab, Prednisone, and Cyclophosphamide. Intern Med. 2017; 56: 2205-11. doi: 10.2169/internalmedicine.8522-16.

7. Igawa T, Sato Y. TAFRO Syndrome. Hematol Oncol Clin North Am. 2018;32:107-118. doi: 10.1016/j.hoc.2017.09.009.

8. Louis C, Vijgen S, Samii K, Chalandon Y, Terriou L, Launay D, et al. taFRo syndrome in Caucasians: a Case Report and 
Review of the Literature. Frontiers in medicine. 2017; 4: 149. doi:10.3389/fmed.2017.00149.

9. Van Rhee F, Greenway A, Stone K. Treatment of Idiopathic Castleman Disease. Hematol Oncol Clin North Am. 2018;32:89-106. doi: 10.1016/j.hoc.2017.09.008.

10. Lin Q, Fang B, Huang H, Yu F, Chai X, Zhang Y, et al. Efficacy of bortezomib and thalidomide in the recrudescent form of multicentric mixed-type Castleman's disease. Blood Cancer J. 2015;5:e298. doi: 10.1038/bcj.2015.12.

11. Yuan Z-g, Dun X-y, Li Y-h, Hou J. Treatment of multicentric Castleman's Disease accompanying multiple myeloma with bortezomib: a case report. J hematol oncol. 2009; 2: 19. doi: 10.1186/1756-8722-2-19. 